\title{
Prospects for economic growth in Punjab under alternative demographic scenarios: The case for a rapid fertility decline
}

David E. Bloom

Zeba Sathar

Population Council

Maqsood Sadiq

Follow this and additional works at: https://knowledgecommons.popcouncil.org/departments_sbsr-rh

Part of the Demography, Population, and Ecology Commons, Family, Life Course, and Society Commons, and the International Public Health Commons How does access to this work benefit you? Let us know!

\section{Recommended Citation}

Bloom, David E., Zeba Sathar, and Maqsood Sadiq. 2015. "Prospects for economic growth in Punjab under alternative demographic scenarios: The case for a rapid fertility decline," Policy brief. Islamabad:

Population Council, The Evidence Project. 
Prospects for Economic Growth in Punjab under Alternative Demographic Scenarios The Case for a Rapid Fertility Decline

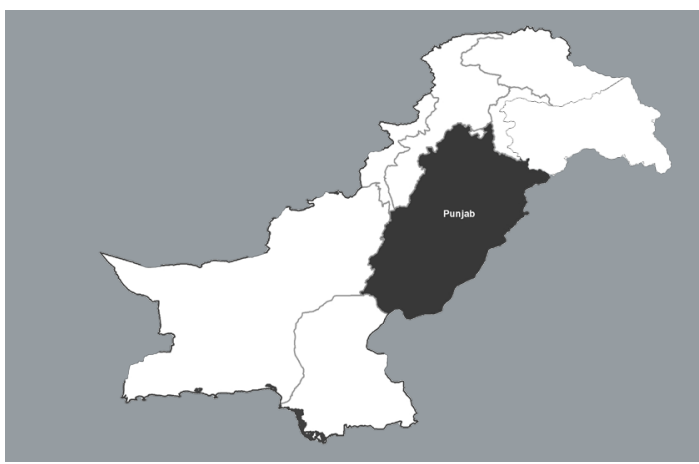

\section{Future economic growth is likely to be closely linked, if not driven, by how rapidly fertility declines further. Bloom, Chen, and Sathar 2015}

While economic growth in Pakistan has averaged 3 percent over the past decade, Vision 2025 envisages it to be over 8 percent between 2018 and 2025. This ambitious target is echoed in the Punjab Growth Strategy 2018, which aims to achieve it by promoting private-sector led and export-oriented economic activity through investments in areas such as institutional and governance reforms, human capital development, improved urban planning, and effective security. Both Vision 2025 and the Punjab Growth Strategy acknowledge that a large and rapidly growing population could hamper growth by pulling investments away from productivity development towards expanding needs for education, health, housing, and other infrastructure. However, they also recognize that inherent within the population challenge is a potentially tremendous opportunity to boost economic growth.

Punjab is currently undergoing a demographic transition from a situation of high fertility and high mortality to one of lower fertility and mortality (Figure 1). The resulting bulge in its working-age population means the province is poised to reap a "demographic dividend"-the boost in income per capita and its growth that accrues when the share of working age individuals in a population rises relative to dependents, resulting in a higher support ratio, ${ }^{1}$ as well as increased labor supply and savings. As the Asian Tigers have demonstrated, a robust working-age population can serve as a potent, real world pathway for achieving economic growth. However, harnessing the powerful thrust of the demographic dividend requires the timely execution of a well-conceived plan of action involving major interventions in the education, health (including reproductive health/population welfare), and labor sectors.

Encouragingly, both Vision 2025 and the Punjab Growth Strategy 2018 show a strong focus on enhancing the productive potential of the current and future work force through investments in education, skills development, and job creation. However, while the need to reduce population growth is recog-
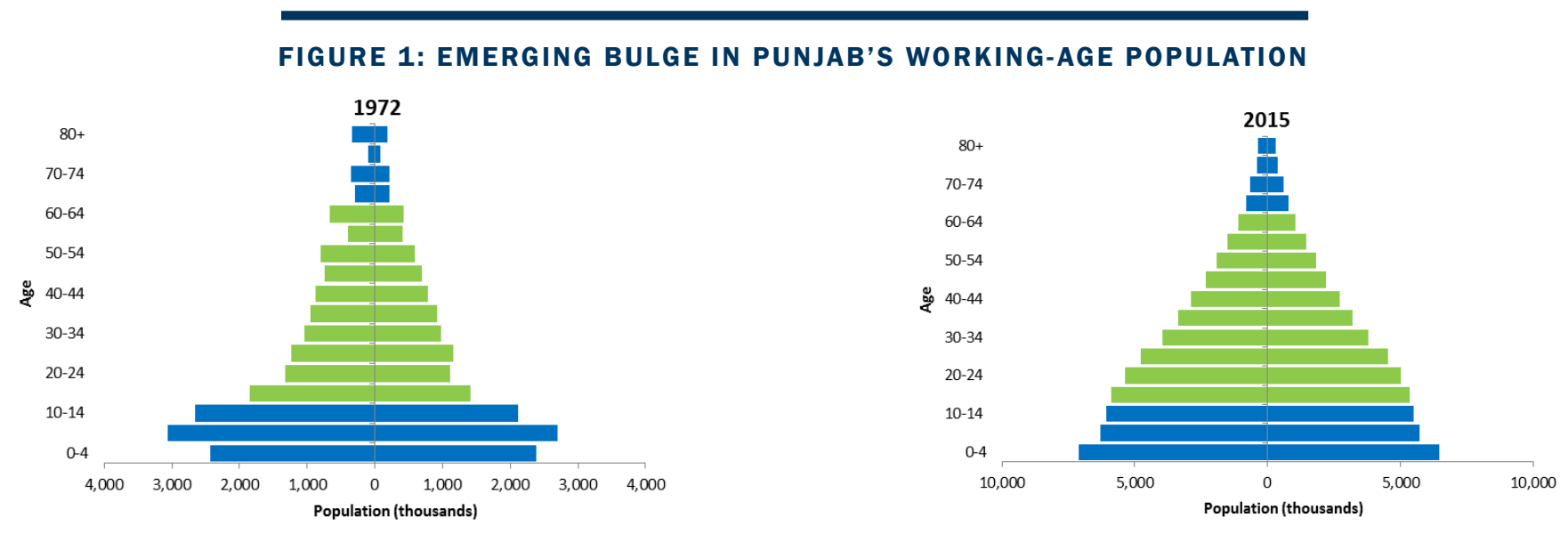

Source: Population Council Projections 2015 
nized intuitively, there is relatively low awareness that the speed at which fertility declines now in Punjab will have a huge impact on the magnitude of the economic boost it is able to reap from the demographic dividend. A recent study of prospects for economic growth in Pakistan under alternative demographic scenarios quantified the massive differences in growth that can be achieved with slow, moderate and rapid fertility decline in Punjab. ${ }^{2}$ This brief presents the study's key findings to facilitate a deeper understanding of the connection between the speed of fertility decline and the size of the demographic dividend, and the scale of the economic gains at stake.

\section{"The need for lowering the growth rate of population is more urgent than ever." \\ VISION 2025}

\section{TABLE 1: PROJECTED DEMOGRAPHICS AND ECONOMIC GROWTH IN PUNJAB IN 2050 WITH SLOW, MODERATE, AND RAPID FERTILITY DECLINE}

\begin{tabular}{|c|c|c|c|}
\hline & $\begin{array}{c}\text { Scenario 1 } \\
\text { Slow Fertility } \\
\text { Decline }\end{array}$ & $\begin{array}{c}\text { Scenario 2 } \\
\text { Moderate } \\
\text { Fertility Decline }\end{array}$ & $\begin{array}{c}\text { Scenario 3 } \\
\text { Rapid Fertility } \\
\text { Decline }\end{array}$ \\
\hline Assume TFR & $\begin{array}{c}\text { Remains 0.5 } \\
\text { births higher } \\
\text { than the mod- } \\
\text { erate decline } \\
\text { assumption }\end{array}$ & $\begin{array}{c}\text { Declines steadi- } \\
\text { ly to 2.1 births } \\
\text { per woman by }\end{array}$ & $\begin{array}{c}\text { Remains 0.5 } \\
\text { births lower } \\
\text { than the mod- } \\
\text { erate decline } \\
\text { assumption }\end{array}$ \\
\hline $\begin{array}{c}\text { Total } \\
\text { Population }\end{array}$ & $\begin{array}{c}183.6 \text { million } \\
\text { Support ratio }\end{array}$ & 172.8 million & 162.5 million \\
\hline Per capita GDP & 1.61 & 1.76 & 1.93 \\
\hline Growth & $333 \%$ & $378 \%$ & $431 \%$ \\
\hline Demographic & $122 \%$ & $168 \%$ & $221 \%$ \\
\hline Dividend & & & \\
\hline
\end{tabular}

Source: Bloom, Chen, and Sathar 2015

\section{FERTILITY DECLINE AND PROSPECTS OF A DEMOGRAPHIC DIVIDEND IN PUNJAB}

As fertility declines in Punjab, the rate of growth in the lowest tiers of its population pyramid (ages 0-14) is slowing down. However, due to the momentum of past high fertility and current improvements in infant and child survival, there will not be an appreciable change in the rate of growth of the working-age population for perhaps two decades. In proportion to dependents, the working-age share of the total population is rising.

To assess the effect of this rising support ratio on future economic growth, Bloom, Chen and Sathar (2015) employed state-of-the-art theoretical and statistical models designed to capture the complexity of economic growth processes and their interactions with demographic trends specific to the $\mathrm{Pa}-$ kistani context. The model is outlined in Box 1. Projections of the total population were generated for three fertility decline scenarios-moderate decline in the total fertility rate (TFR) from the current level of 3.8 to replacement fertility (TFR 2.1) in 2050; 3 slow decline in TFR, which would mean that replacement fertility is reached sometime after 2050; and rapid decline in TFR, implying that replacement fertility is attained before 2050. For population projections, the base year was 1998, when the last census was conducted, while 2011 was taken as the base year for the per capita income and demographic dividend comparison. The results of the study for Punjab are summarized in Table 1.

As shown in Figure 2, depending on the speed of fertility decline, the population of Punjab could grow to 184 million or to 162 million by 2050. Compared to a scenario of rapid fertility decline, slow fertility decline implies approximately 15 million more young dependents in the population. This will translate into a lower support ratio-1.61, as against 1.93 with rapid fertility decline (Table 1).

A higher support ratio represents an increase in the productive capacity of the economy on a per capita basis, which creates the prospect of a spurt in economic growth-the demographic dividend. To maximize the size of the demographic dividend, the support ratio must be maintained at optimal levels while the "boom" in the working-age population lasts. Fertility must decline as much as possible to raise the support ratio, and as fast as possible to allow the high support ratio to prevail over a longer period. Figure 3 presents the historical and prospective trend in Punjab's support ratio and how it is affected by the pace of fertility decline. Notably, the support ratio started to rise in the late 1990s-when energetic efforts were made to increase uptake of family planningbut it is now beginning to plateau. It can be expected to rise significantly if a moderate or rapid pace of fertility decline is achieved.

Differences in the support ratio, in turn, lead to wide divergences in the per capita GDP growth attainable (Figure 4). In 2050, per capita income in Punjab is expected to be 
FIGURE 2: PROJECTED POPULATION GROWTH IN PUNJAB WITH SLOW, MODERATE, AND RAPID FERTILITY DECLINE

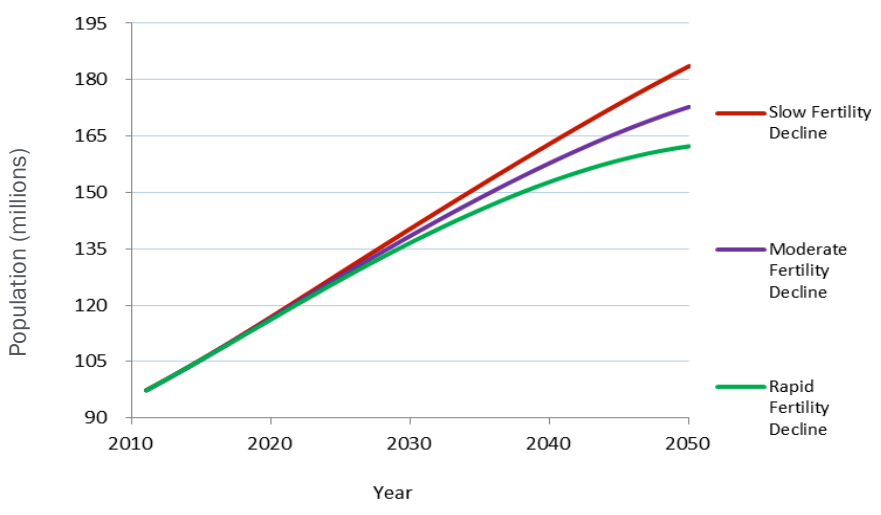

Source: Bloom, Chen, and Sathar 2015

FIGURE 3: HISTORICAL TRENDS AND PROJECTED GROWTH IN PUNJAB'S SUPPORT RATIO WITH SLOW, MODERATE, AND RAPID FERTILITY DECLINE

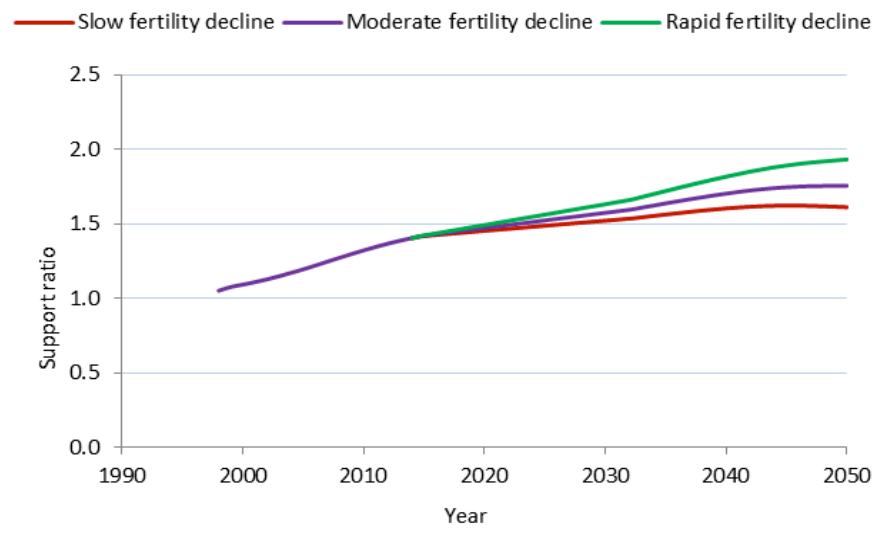

Source: Bloom, Chen, and Sathar 2015

FIGURE 4: PROJECTED PER CAPITAL GDP GROWTH IN PUNJAB WITH SLOW, MODERATE, AND RAPID FERTILITY DECLINE

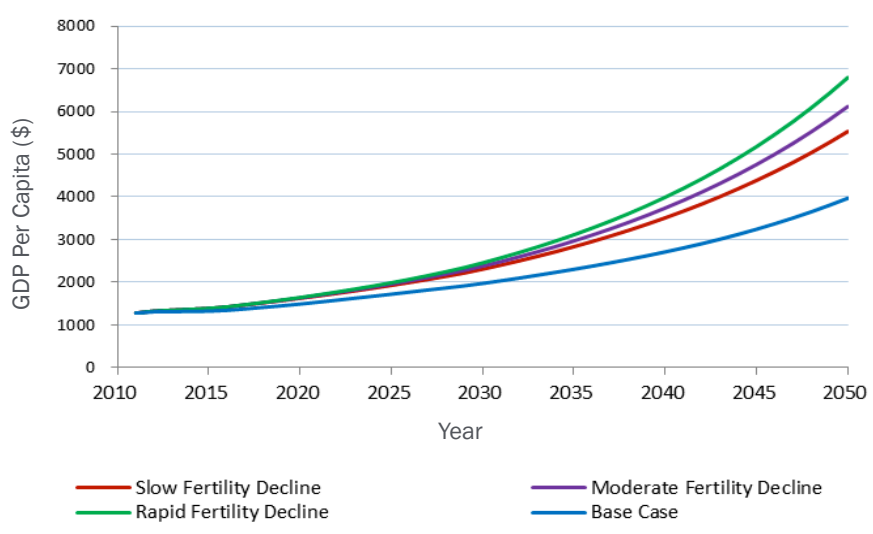

Source: Bloom, Chen, and Sathar 2015 about $\$ 4,000$ if fertility persists at current levels; a little over $\$ 5,500$, if fertility declines slowly; and about $\$ 6,800$, if fertility drops rapidly.

This means that if the fertility rate continues to hover in the current vicinity of 3.8, Punjab's GDP per capita will only be about 210 percent greater in 2050 than it is today; however, if the TFR declines rapidly, Punjab's GDP per capita could grow by as much as 431 percent. In other words, a precipitous decline in fertility could boost income in Punjab by 221 percent over current levels, independent of any additional income growth that occurs over this horizon. By comparison, a slow decline in fertility would lead to a 122 percent boost in income, which, significant as it is, represents only about half of the dividend achievable.

The results show that, overall, for every one unit of decrease in the total fertility rate, GDP per capita is expected to increase by $90-100$ percent. Further fertility decline is going to be associated with a rise in per capita income, but the level of benefits to be accrued will multiply if there is a serious effort at interventions that speed up the decline while the support ratio is elevated. This is a strong economic argument for investing in a more rapid fertility decline in the province.

\section{"Our Vision today is to make Pakistan the next Asian Tiger." \\ VISION 2025}

\section{POLICY IMPLICATIONS}

By 2050, Punjab's per capita income will be 210 percent higher than today's levels if there is no decline in fertility, but 431 percent higher if fertility declines rapidly. The scale and effectiveness of efforts to reduce fertility levels in Punjab will determine whether per capita income in the province grows by 333 percent or by 431 percent by 2050 . The possible demographic dividend of a 221 percent increase in per capita income is simply too huge to be ignored in economic growth strategy, especially given Punjab's burgeoning population, resource constraints, and development aspirations. The findings presented in this brief show clearly that, if Punjab is to harness the demographic dividend, planners must invest at least as heavily and urgently in efforts to raise the contraceptive prevalence rate (CPR) as in interventions to educate, train and productively employ the youth bulge.

Time is of the essence. The demographic dividend is a limited-time offer, and once fertility reaches replacement levels, the demographic transition model predicts some semblance 
of equilibrium between fertility and mortality levels. By 2040 , the bulge that is currently in the working-age tiers will have progressed through to older tiers of the pyramid, while a reduced population of young people will have entered Punjab's work force. Accordingly, the support ratio will decline and the dividend window will close.

\section{"The speed at which fertility declines now in Punjab will determine the magnitude of the economic boost it will experience."}

Punjab must act fast to lower its TFR and maintain a high support ratio through what is left of the dividend period. The process can be kick-started by focusing on eliminating unmet

\section{BOX 1: MODEL USED TO PROJECT PROSPECTS FOR
ECONOMIC GROWTH UNDER ALTERNATIVE \\ BOX 1: MODEL USED TO PROJECT PROSPECTS FOR
ECONOMIC GROWTH UNDER ALTERNATIVE DEMOGRAPHIC SCENARIOS}

need for family planning, which is estimated at 18 percent, and represents an opportunity for a rapid demand-driven increase in Punjab's CPR from the current level of 41 percent to 59 percent. This alone will reduce the TFR from 3.8 to the wanted level of fertility of 2.8 (PDHS 2013). In comparison, the Punjab government's FP2020 goal of raising the CPR to 55 percent by 2020 will reduce the TFR to 2.9. While increased investment in family planning will be entailed in eliminating unmet need, and further efforts will be needed to ensure a continuation of the rapid fertility decline trajectory, the costs are more than justified by the substantially large economic boost achievable.

\section{ENDNOTES}

(1) The support ratio expresses the proportion of working-age individuals relative to dependents in the population. It is defined here as the working age population (15-59) divided by the non-working age population (<15 or $>59$ years). (2) D. E.

Bloom, S. Chen and Z. Sathar, "Prospects for economic growth in Pakistan under alternative demographic scenarios" (Population Council, Islamabad). (3) The TFR measures the average number of children expected to be borne by every woman in a population during her lifetime. The model's TFR assumptions for the three fertility decline scenarios are indicated in Table 1.

GDP growth estimations in the model follow the convergence model proposed by Barro (2004). The final multiple regression growth equation is derived by manipulating the Solow growth model and states the determinants of the growth of income per capita.

$$
\dot{y} t=-\alpha y_{t}+\beta w_{t}+\delta \dot{w}_{t}+\delta I_{t}+\eta^{T} X_{t}+\epsilon_{t}
$$

Where $y t=\log \left(\frac{Y t}{P t}\right)(Y$ is aggregate income $), w=\log \left(\frac{Y t}{L t}\right)(L$ is labor force $)$ and $X_{t}$ denotes time-variant control variables other than demographic variables.

The model assumes Sindh's total fertility rate, which currently stands at about 3.9 children per woman, will decline to the long-run replacement level of 2.1 children per woman. The model also assumes that life expectancy in Sindh will increase to 69 years by 2050.

To test the sensitivity to fertility rates, three fertility decline scenarios are considered:

1. Moderate fertility decline (Medium Variant), which assumes that the TFR declines at a steady pace and reaches replacement level (2.1 births per women) by 2050.

2. Rapid fertility decline (Low Variant), which assumes that TFR is $\mathbf{0 . 5}$ births lower than under the medium fertility (1.6 births per woman) assumption throughout.

3. Slow fertility decline (High Variant), which assumes that the TFR is $\mathbf{0 . 5}$ births higher than under the medium fertility (2.6 births per woman) assumption throughout.

An indicator "IDD" is introduced, which measures the relative size of demographic dividend and is defined as

$$
\text { IDDi }=\frac{y_{2050}^{i}-y^{0}}{y_{2050}}
$$

Where $\mathrm{y}_{2050}^{\mathrm{i}}$ is the GDP per capita in 2050 under scenario $\mathrm{i}, \mathrm{y}^{0}{ }_{2050}$ is the GDP per capita in 2050 in base case scenario and $\mathrm{y}_{2011}$ is the GDP in the staring year.

Source: Derived from Bloom, Chen, and Sathar (2015).

\section{THE EVIDENCE PROJECT} Population Council House No. 7, Street No. 62 Section F-6/3

Islamabad, Pakistan

tel +92 518445566 evidenceproject.popcouncil.org

CONTRIBUTORS

Dr. Zeba A. Sathar (T.I.) Dr. David Bloom Maqsood Sadiq

\section{(3). USAID} The Evidence Project is made possible by the generous support of the American people through the United States Agency for International Development (USAID) under the terms of cooperative agreement no. AID-OAA-A-13-00087. The contents of this document are the sole responsibility of the Evidence Project and Population Council and do not necessarily reflect the views of USAID or the United States Government. Evidence idence-to strengthen and scale up family planning and reproductive health prosstation, and use of ev tended pregnancies worldwide. The Evidence Project is led by the Population Council in partnership with INDEPTH Network, International Planned Parenthood Federation, Management Sciences for Health, PATH, Population Reference Bureau, and a University Research Network.

() 2015 The Population Council, Inc. 